\title{
Radial maze performance in inbred mice: Evidence for strain-dependent neural nets subserving spatial learning abilities
}

\author{
CLELIA ROSSI-ARNAUD \\ Consiglio Nazionale delle Ricerche and Università di Roma "La Sapienza," Rome, Italy \\ and \\ MARTINE AMMASSARI-TEULE \\ Consiglio Nazionale delle Ricerche, Rome, Italy
}

\begin{abstract}
C57BL/6 (C57) and DBA/2 (DBA) inbred mice perform differently on spatial tasks, with C57 mice doing better than DBA ones. Previous results have shown that hippocampal lesions impair performance in a radial eight-arm maze in both strains, while amygdaloid and frontal-cortex lesions have a deleterious effect only in the "high-learner" C57 strain. The high spatial-learning abilities of C57 mice seem, therefore, to be based upon a neural net recruiting distinct brain areas. The aim of the present study was to examine whether the genotype-dependent involvement of brain structures remains the same in radial-maze tasks with procedures that reduce or abolish interstrain performance differences. C57 and DBA mice with hippocampal, amygdaloid, or sham lesions were tested in a spatial (Experiment 1) or a visually cued (Experiment 2) version of the 4-baited-arm task using a radial 8-arm maze. No interstrain difference in baseline performance was observed in the two tasks. In the spatial discrimination task, hippocampal lesions impaired performance in both strains, while amygdaloid lesions had a selective deleterious effect on reentry into baited arms in the C57 strain only. Hippocampal but not amygdaloid lesions impaired performance on the visual discrimination task in both strains. Spatial, but not visual, discriminative learning seems, therefore, to involve a different circuitry according to the strain considered. The question of whether the areas recruited for each circuit cooperate by processing distinct but complementary memory attributes or whether they are simply vicariant may have strong implications for studies concerning functional recovery.
\end{abstract}

Every form of learning process necessarily results from the integration of several functions, each being more specifically controlled by a particular brain area. In the case of spatial learning, evidence first accumulated indicating that the hippocampus was primarily involved in mediating performance (see Olton, Becker, \& Handelmann, 1979, for a review). More recent results have shown a modulatory role for thalamic (Greene \& Naranjo, 1986; Kolb, Pittman, Sutherland, \& Whishaw, 1982), basal forebrain (Dunnett, Whishaw, Jones, \& Bunch, 1987), striatal (Packard \& White, 1990), and cortical structures (Kesner, Farnworth, \& DiMattia, 1989; Poucet, 1990). These results were obtained by lesioning discrete brain areas in individuals belonging to outbred populations. Statistical evaluation of these effects was therefore based upon the assumption that within-group differences in both baseline performance and the reactivity to lesions were distributed normally.

Fundamental differences exist, at the methodological level, between these studies and those using inbred strains.

This research was supported by a grant to the first author from Sigma Tau Foundation, Rome, Italy. Correspondence should be addressed to C. Rossi-Arnaud, Istituto di Psicobiologia e Psicofarmacologia, Via Reno, 1, 00198 Rome, Italy (e-mail:a13900@irmcnr).
In the latter case, since individuals belonging to the same strain possess the same genotype, within-group behavioral and neural differences are assumed to be minimal, while between-group - that is, interstraindifferences reflect the variability evident in a natural (feral) population. It is therefore possible to segregate high- and low-learner strains for particular tasks and search for the neural mechanisms that more specifically subserve each level of performance.

C57BL/6 (C57) mice solve several spatial tasks better than $\mathrm{DBA} / 2 \mathrm{~J}$ (DBA) mice. This superiority in performance is evident in both the standard version of the radial maze (Ammassari-Teule \& Caprioli, 1985; Crusio, Schwegler, \& Lipp, 1987) and the Morris water task (Upchurch \& Wehner, 1989). Interestingly, lesions to limbic or cortical areas in these strains have revealed a genotype-dependent pattern of effects on radial-maze performance. Whereas hippocampal lesions impair performance in both strains, amygdaloid and frontal cortex lesions have a deleterious effect only in the high-learner C57 strain (Ammassari-Teule \& Gozzo, 1982; RossiArnaud, Fagioli, \& Ammassari-Teule, 1991). On the basis of these observations, it has been suggested that the high and low spatial-learning abilities found, respectively, in C57 and DBA mice might be based upon circuits re- 
cruiting distinct brain areas (Ammassari-Teule, Fagioli, \& Rossi-Arnaud, 1992).

It must be noted, however, that the expression of a strain-dependent behavioral trait can vary according to the characteristics of the experimental situation. In a discrimination leverpress avoidance task, interstrain differences in performance were reduced or eliminated by increasing the duration of the unconditioned stimulus (Renzi \& Sansone, 1971). In the same way, when mice had to identify only 4 baited arms in a radial 8 -arm maze, the superiority of C57 mice was evident only in the first half of the training period. Further, when the visual, rather than the spatial, modality was relevant in discriminating the the baited arms, the learning curves of C57 and DBA mice became indistinguishable (AmmassariTeule, Hoffmann, \& Rossi-Arnaud, 1993).

Following from these findings, the aim of the present experiments was to examine whether the genotypedependent involvement of limbic structures in radialmaze learning remains the same across tasks which diminish or abolish interstrain differences in performance, (1) by limiting the number of correct arms to discriminate within the spatial modality, or (2) by shifting from the spatial to the visual modality. As a working hypothesis, we assumed that the strain-dependent neural nets subserving radial-maze learning might be less differentiated when the demand of the task causes strain-dependent learning abilities not to be evident.

\section{METHOD}

\section{Subjects}

The subjects were 64 male C57BL/6 mice and 64 male DBA/2 mice, purchased from the Charles River laboratory (Como, Italy). Thirty-two of each strain were used for each experiment. At the start of the experiments, their ages were approximately 70 days and their weights ranged from 23 to $28 \mathrm{~g}$. The animals were individually housed in transparent Plexiglas cages placed in an experimental room with a 12:12-h light:dark cycle with lights on from 0700 to $1900 \mathrm{~h}$. Before pretraining, mice were food deprived in order to gradually bring down their weight to $85 \%$ of its initial level.

\begin{abstract}
Apparatus
The apparatus used in the two experiments was a gray plastic maze with 8 identical arms radiating from an octagonal starting platform (perimeter $7 \times 8 \mathrm{~cm}$ ), like the spokes of a wheel. Each arm was $38 \mathrm{~cm}$ long $\times 7 \mathrm{~cm}$ wide. A food cup, $1 \mathrm{~cm}$ deep and $2 \mathrm{~cm}$ in diameter, was inserted in the floor of the maze at the distal end of each arm. The entire maze was elevated $60 \mathrm{~cm}$ above the floor and placed in a well-lit room which had several extramaze cues, consisting of a fluorescent light, a door, two pieces of black cloth on two of the walls, and the experimenter. The maze was maintained at a constant orientation during all experiments.

For the cued version (Experiment 2), eight removable inserts $(32 \times 7 \mathrm{~cm})$ were made by gluing different materials (sandpaper, mesh wire, and papers with different patterns painted on them) to a cardboard backing. In order to eliminate the preference shown in a preliminary experiment for inserts with specific tactile features-namely, sandpaper and mesh wire - they were all covered with a transparent plastic coating (Figure 1).
\end{abstract}

\section{Experimental Design}

On each experiment, 16 mice ( 8 from each strain) were initially assigned to each lesion condition. Postsurgery loss of animals led to the following unequal number of subjects: Experiment 1, hippocampal lesions $=8 \times \mathrm{C} 57$ and $8 \times \mathrm{DBA}$, sham hippocampal lesions $=8 \times \mathrm{C} 57$ and $6 \times \mathrm{DBA}$, amygdaloid lesions $=7 \times \mathrm{C} 57$ and $8 \times \mathrm{DBA}$, and sham amygdaloid lesions $=8 \times \mathrm{C} 57$ and $7 \times$ DBA; Experiment 2, hippocampal lesions $=8 \times \mathrm{C} 57$ and $8 \times$ DBA, sham hippocampal lesions $=8 \times \mathrm{C} 57$ and $6 \times \mathrm{DBA}$, amygdaloid lesions $=7 \times \mathrm{C} 57$ and $7 \times \mathrm{DBA}$, and sham amygdaloid lesions $=7 \times \mathrm{C} 57$ and $7 \times$ DBA.

\section{Surgery}

Mice were anesthetized with chloral hydrate $(400 \mathrm{mg} / \mathrm{kg})$ and placed in a Narishige stereotaxic apparatus with mouse adaptor. The scalp was incised and retracted and holes were drilled through the skull at points above the intended sites of lesions. A 0.15 -mm-diam stainless-steel electrode, insulated except at the tip, was inserted bilaterally in the following areas with lambda and bregma in the same horizontal plane: amygdaloid complex (posterior to bregma, $-1.2 \mathrm{~mm}$; lateral from midline, $\pm 3.6 \mathrm{~mm}$; ventral from the dural surface, $5 \mathrm{~mm}$ ); and hippocampus (posterior to bregma, $-1.8 \mathrm{~mm}$; lateral from midline, $\pm 2 \mathrm{~mm}$; ventral from the dural surface, $2.2 \mathrm{~mm}$ ). A $2.5-\mathrm{mA}$ anodal current was passed through the electrode for $6 \mathrm{sec}$. The circuit was completed by taping the cathode to the tail. Sham lesions were performed whereby the electrode was inserted at the coordinates used for lesioning, but to a depth of only of $0.5 \mathrm{~mm}$, so that electrocoagulation was not induced. At the completion of surgery, the scalp was sutured closed. The subjects were then left in their home cages for a recovery period of one week.

\section{Pretraining}

The day before training began, each mouse was placed on the starting platform of the apparatus and allowed to explore and to consume pieces of food scattered in the whole maze for $5 \mathrm{~min}$.

\section{Training Procedure}

Experiment 1: 4-baited-arm maze. On each trial, only 4 arms were baited, each with a $30-\mathrm{mg}$ piece of Purina Lab Chow. The

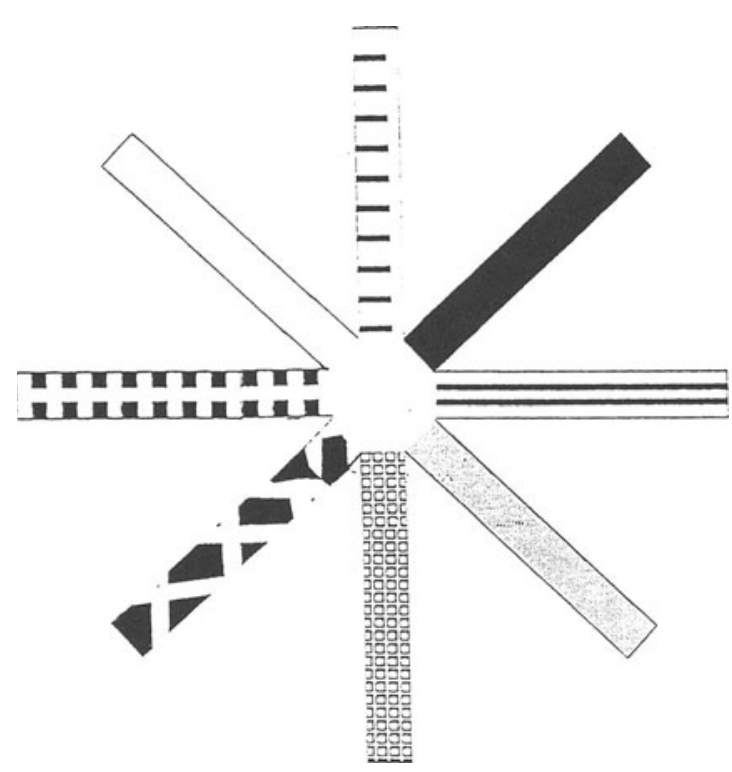

Figure 1. Radial 8-arm maze with visual patterns. The four patterns predicting reinforcement throughout the experiment were randomly chosen for each mouse. The arms were numbered from 1 to 8 , and, before each trial, each pattern was randomly assigned to one of the 8 arms. 

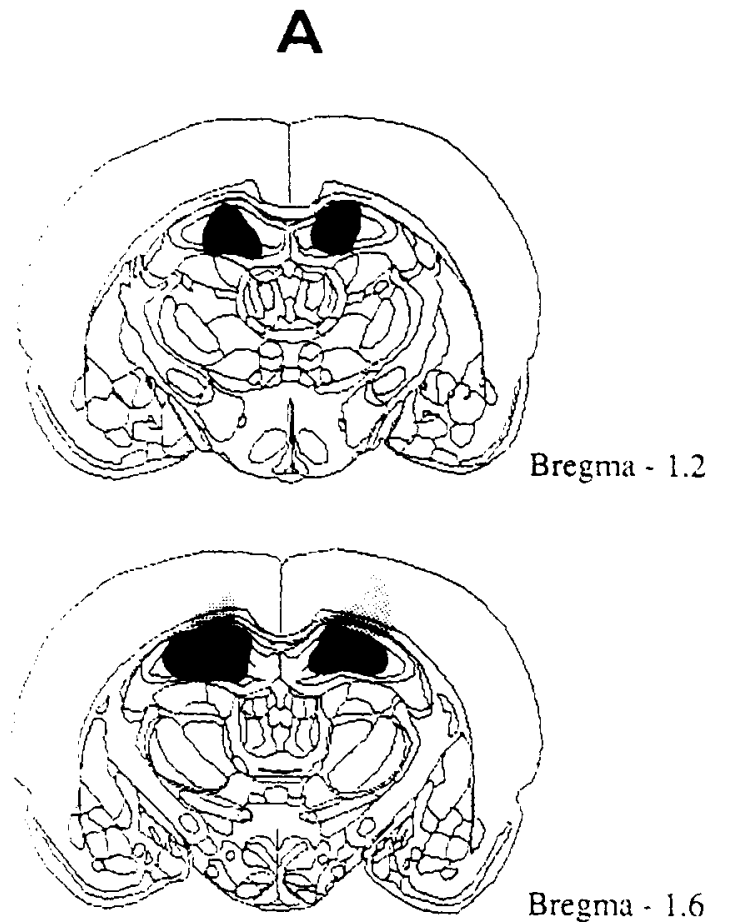

Bregma - 1.6

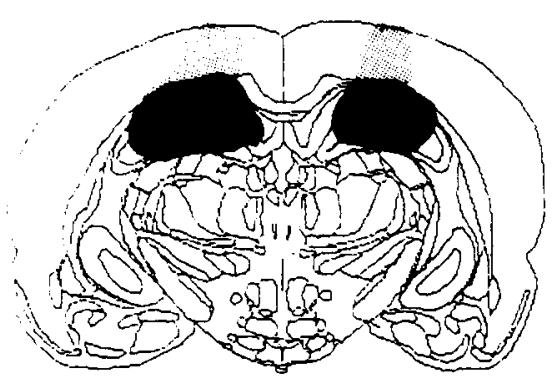

Bregma - 2.0

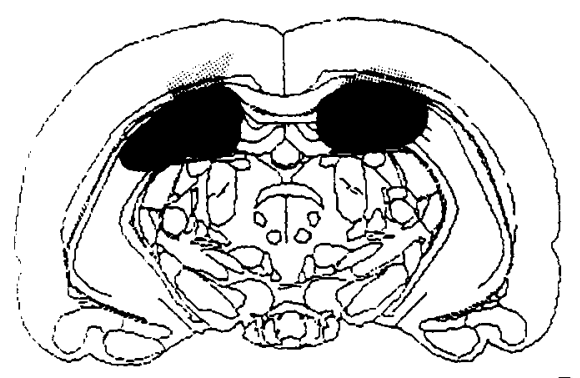

Bregma - 2.5

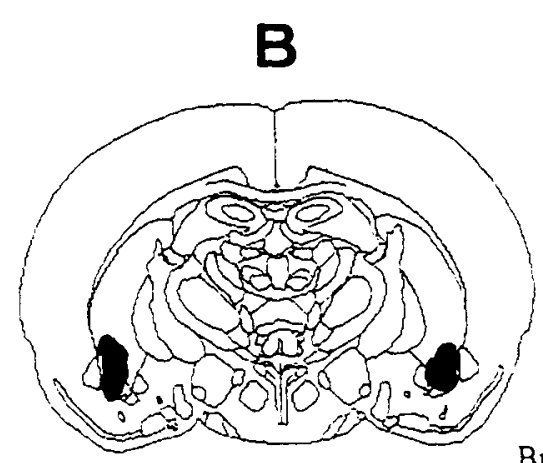

Bregma -0.8

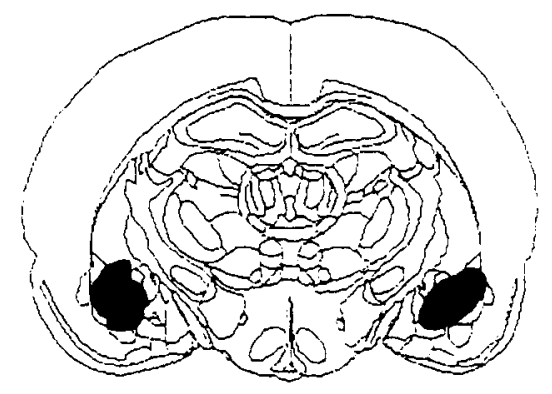

Bregma - 1.2

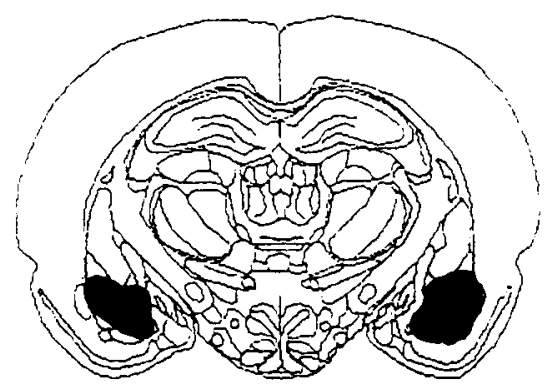

Bregma -1.6

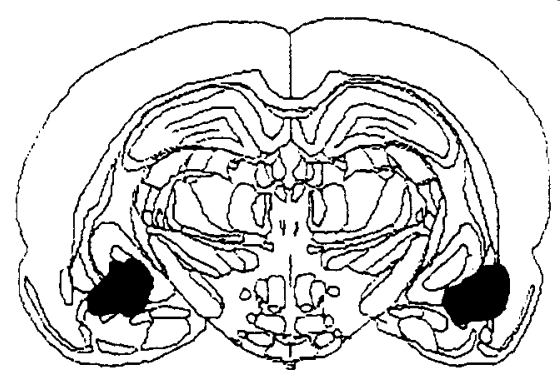

Bregma - 2.0

Figure 2. Representation of histologically verified hippocampal (A) and amygdaloid (B) bilateral lesions in successive brain sections. The gray area and the dark area represent the largest and smallest extent of the damage, respectively.

baited arms were separated by different angles $\left(45^{\circ}, 90^{\circ}, 90^{\circ}\right.$, and $145^{\circ}$ ) in order to prevent the mice from reaching the solution through the adoption of clockwise patterns. Olfactory cues were mixed by baiting different sets of arms for different individuals of each group, with the same set being used for each mouse throughout the experiment. Further, between successive mice, the maze was cleaned with alcohol. On each trial, the mouse was placed on the central platform of the maze and allowed to enter the arms until the four pieces of food had been collected within a maximum of $16 \mathrm{arm}$ entries. An error occurred when the animal completely entered an arm that had already been visited during that particular trial. A trial was correctly executed when the mouse entered only the 4 baited arms and each arm was visited only once. The mice went through one learning trial per day during 14 consecutive days. Reentries made into previously visited baited and unbaited arms were recorded.

Experiment 2: Cued 4-baited-arm maze. For each mouse, the baited arms were indicated by four visual patterns--the same four were used throughout the experiment-randomly extracted out of eight. The eight patterns were then moved randomly from trial to 
trial in order to form a trial-dependent configuration differing for each individual. The remaining procedure was the same as in Experiment 1 . Reentries made into previously baited and unbaited arms were recorded.

\section{Data Analysis}

Errors were broken down as follows: (1) reentries into baited arms; (2) first visits to unbaited arms; and (3) reentries into unbaited arms. Separate three-way mixed factorial analyses of variance (ANOVAs), with two between-group factors--strain (two levels: C57 and DBA) and lesion (four levels: hippocampal lesions, sham hippocampal lesions, amygdaloid lesions, and sham amygdaloid lesions) - and one within-group factor-trial ( 14 levels)were performed for each type of error. The analysis of simple main effects and the Tukey test were used for post hoc comparisons where necessary.

\section{RESULTS}

\section{Histology}

At the completion of the experiments, lesioned and sham-lesioned mice were sacrificed under chloralhydrate anesthesia. The brains were fixed in formalin ( $10 \%$ solution), sectioned coronally $(60 \mu)$, and stained with toluidine blue, according to the Nissl method. Figure 2 shows typical hippocampal and amygdaloid lesions. Examination of the tissue revealed lesions to the dorsal hippocampus, some of which damaged the corpus callosum situated above, and lesions to the central nucleus of the amygdala that extended, in some cases, to the basolateral nucleus. A similar pattern of bilateral damage of the neural tissue was observed in both strains.

\section{Behavior}

Experiment 1. The data are presented graphically in Figures 3 and 4 . When reentries into baited arms errors were analyzed, statistical analysis indicated that performance improved with training in all groups-that is, that there was a significant main effect of trial $[F(13,676)=$ $3.49, p<.001]$. The analysis also revealed a significant main effect of lesion $[F(3,52)=23.77, p<.001]$ and a significant strain $\times$ lesion interaction $[F(3,52)=3.34$, $p<.05]$. Post hoc comparisons indicated that, while hippocampal lesions impaired performance in both strains (C57: $p<.01$; DBA: $p<.05$ ), the impairing effect of amygdaloid lesions on performance was limited to the C57 strain. Lesioned mice from this strain differed from their respective controls $(p<.05)$. No difference was found between the four groups of sham-lesioned animals.

The analysis performed on the errors consisting of a first visit to an unbaited arm showed that performance improved with training $[F(13,676)=2.92, p<.001]$ and that lesioned mice did not differ from their controls. Indeed, the main effect of lesion revealed by the analysis $[F(3,52)=3.17, p<.05]$ is, in fact, due to hippocampuslesioned animals which differ from sham-amygdalalesioned mice $(p<.05)$.

Finally, analysis performed on the errors consisting of a reentry into an unbaited arm showed a significant main effect for lesion $[F(3,52)=21.59, p<.001]$. Post hoc comparisons indicated that only hippocampal lesions im-
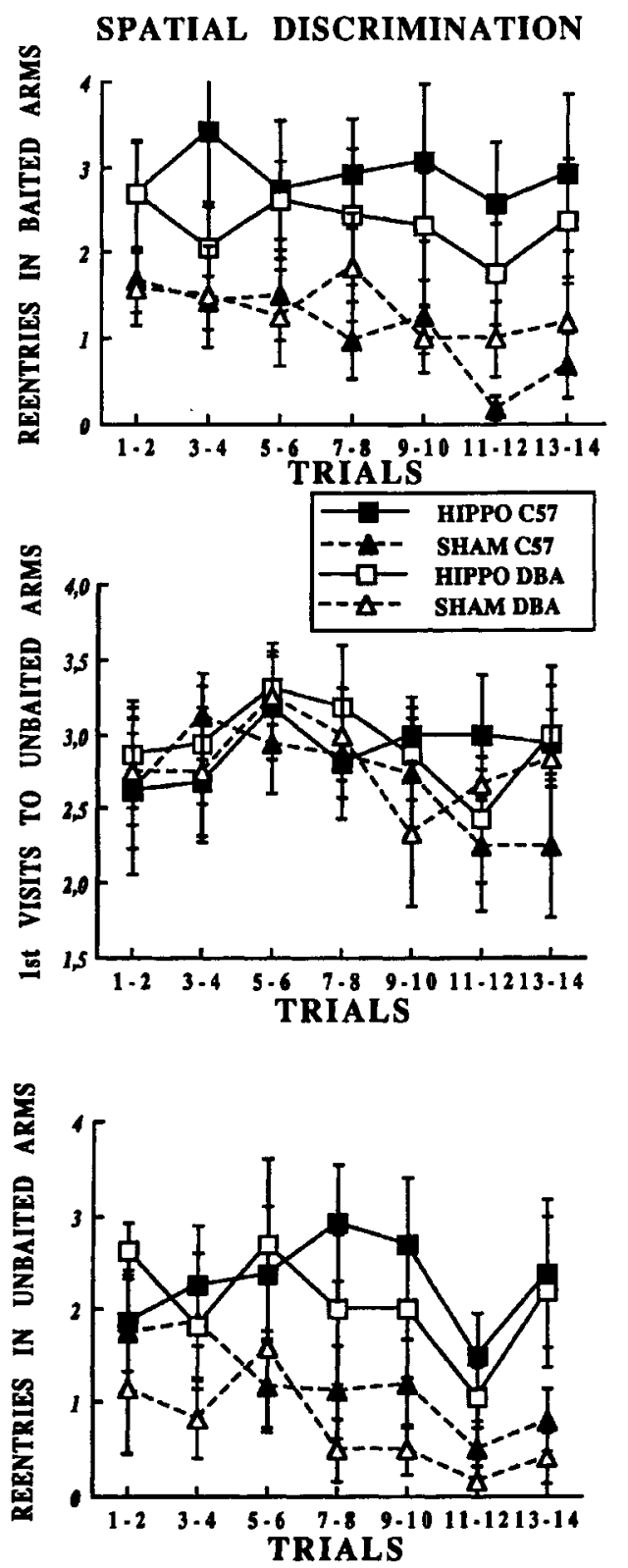

Figure 3. Spatial discrimination performance in hippocampusand sham-lesioned C57 and DBA mice: number of reentries made in baited arms (top), first visits to unbaited arms (middle), and number of reentries in unbaited arms (bottom). Each point corresponds to the mean $\pm S E M$ recorded on two consecutive daily trials (statistical analysis was performed on single trial values).

pair performance on this parameter $(p<.01)$ in both strains. Regarding training, a main effect for trial $[F(13,676)=5.23, p<.001]$ and a lesion $\times$ trial interaction $[F(39,676)=1.44, p<.05]$ were found. A simple main-effect analysis indicated that training had a marginal effect on the two sham groups and a significant effect on the two lesioned groups [hippocampus: $F(39,676)$ $=3.09, p<.001$; amygdala: $F(39,676)=2.37, p<.01$ ]

Experiment 2. The data are presented graphically in Figures 5 and 6 . When reentries into baited arms errors 

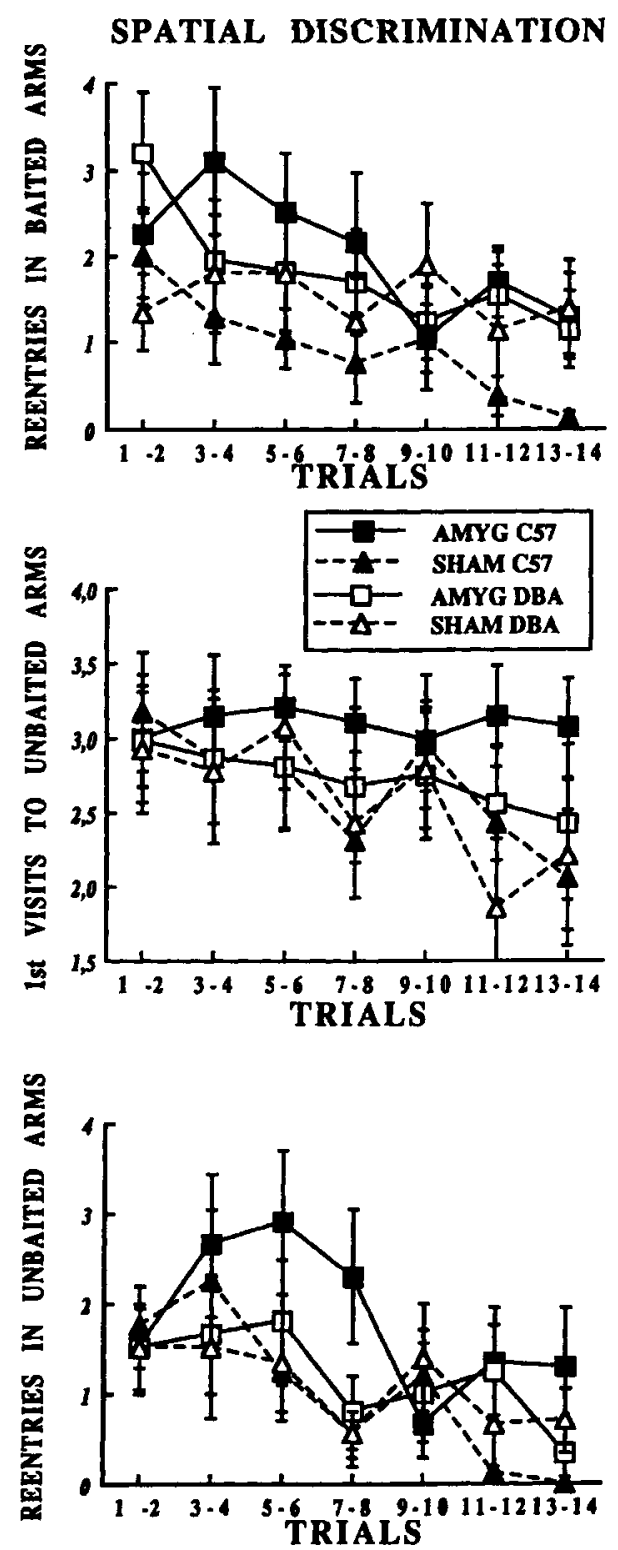

Figure 4. Spatial discrimination performance in amygdala- and sham-lesioned C57 and DBA mice: number of reentries in baited arms (top), first visits to unbaited arms (middle), and number of reentries in unbaited arms (bottom). Each point corresponds to the mean $\pm S E M$ recorded on two consecutive daily trials (statistical analysis was performed on single trial values).

were analyzed, statistical analysis indicated that performance improved with training in all groups - that is, that there was a significant main effect of trial $[F(13,650)=$ $6.71 p<.001]$. The analysis also revealed a significant main effect of lesion $[F(3,50)=10.25, p<.001]$. Post hoc comparisons indicated that, in both strains, the performance of hippocampus-lesioned mice differed from that of their controls $(p<.01)$, while no difference was found either between amygdala-lesioned mice and their controls or between the four groups of sham-lesioned animals.
The analysis performed on errors consisting of a first visit to an unbaited arm showed that performance improved with training $[F(13,650)=1.94, p<.05]$, that C57 mice made more first visits to unbaited arms than DBA mice $[F(1,50)=6.87, p<.05]$, and that lesioned mice did not differ from their respective controls. Indeed, regarding the last point, post hoc comparisons indicated that the main effect of lesion revealed by the analysis $[F(3,50)=3.4, p<.05]$ was, in fact, due to hippocampus-lesioned animals which differed from sham-amygdala-lesioned mice $(p<.05)$.

Finally, the analysis performed on errors consisting of a reentry into an unbaited arm showed significant main effects for trial $[F(13,650)=9.48, p<.001]$ and for lesion $[F(3,50)=14.3, p<.001]$. Post hoc comparisons indicated that, in both strains, only hippocampal lesions impaired performance on this parameter $(p<.01)$. No difference was found between the four sham groups.

\section{DISCUSSION}

The results of Experiment 1 indicate that in both strains, hippocampal lesions impaired spatial discrimination performance by increasing reentries into both baited and unbaited arms. The effect of amygdaloid lesions is more selective: it was evident in the C57 strain only, and exclusively concerned reentries into previously baited arms. Finally, the number of first visits to unbaited arms was unaffected by any lesion. These and previous data on the amygdala (Rossi-Arnaud et al., 1991) and the frontal cortex (Ammassari-Teule \& Gozzo, 1982) indicate that C57 performance in spatial tasks is more sensitive to brain lesions, even when the reinforcement schedule -4 baited arms instead of 8-does not allow strain differences in baseline scores to be observed.

This last point does not fully support previous data (Ammassari-Teule et al., 1993) showing a slight but significant superiority of $\mathrm{C} 57$ mice in the 4-baited-arm task during the first half of the training period. Such results, however, were obtained in nonlesioned, rather than sham-lesioned, mice, and no limit of runs was imposed within the trials. Interestingly, the fact that C57 and DBA mice display the same baseline performance eliminates the possibility that the insensitivity of DBA spatial learning performance to amygdaloid lesions (Rossi-Arnaud et al., 1991) might be due to a floor effect.

According to a large body of data from the literature (see Olton, 1983, for a review), the increase of reentries into baited arms shown by amygdala-lesioned C57 mice should be viewed as a specific working-memory deficit. It appears, however, that, within a trial, there is currently less agreement on the rigid correspondence between a particular type of error and a given memory process. If working memory is responsible for the temporal storage of trial-dependent events, reentries into arms, whether baited or unbaited, have to be considered working-memory errors (Marighetto, Micheau, \& Jaffard, 1993). An alternative explanation to one based on working-memory 
deficits is that the higher number of reentries into baited arms could indicate that amygdala-lesioned C57 mice (1) are able to discriminate between the two sets of arms on the basis of their different reinforcing properties, but (2) are impaired in their ability to inhibit their responses toward the positively reinforced arms. A lack of drive reduction following food consumption could account for this disinhibition. Regardless of which explanation is correct, the effect of amygdaloid lesions on the parameter of reentries into baited arms by C57 mice appears somewhat transient and is smaller in magnitude than that produced in the same strain by hippocampal lesions. As previously suggested (Rossi-Arnaud et al., 1991), it therefore seems that the hippocampus has a more predominant role than the amygdala in the spatial behavior of C57 mice.

Adding visual stimuli to the arms and moving them randomly across trials turned the previous spatial task into a visual-discrimination task (Experiment 2). Results from this experiment show (1) a similar baseline performance in sham-lesioned C57 and DBA mice, (2) an impairing effect of hippocampal lesions on reentries into baited as well as into unbaited arms in both strains, and (3) no effect of amygdala lesions. The first observation confirms previous results showing that $\mathrm{C} 57$ and DBA mice performed in the same fashion when salient visual stimuli were provided as discriminative intramaze cues (Ammassari-Teule et al., 1993). The second observation, however, does not fit with data from the literature indicating that hippocampal lesions did not affect the performance of rats in the cued maze (Jarrard, 1986; Winocur, 1982).

This discrepancy is particularly intriguing since mice, with lesions restricted to the dorsal hippocampus, were impaired in this task, while rats, with a complete hippocampectomy, did not show any deficit. It must be noted, however, that previously described effects of hippocampal lesions on exploratory tendencies (Ammassari-Teule \& Maho, 1992; Roberts, Dember, \& Brodwick, 1962) and free-choice patterns (Kimble, 1975) may introduce some bias on maze performance by affecting response control. A possible explanation of our results could be that, in the cued version of the task, mice rely on visual information to a lesser extent than rats and, consequently, are more sensitive to the effect of hippocampal lesions on response control.

Further, the results of the present study do not indicate any effect of amygdala lesions on the performance of both strains in the cued maze. To date, studies on the effect of amygdaloid damage on visual discrimination learning have yielded conflicting results that vary with the species and the task considered. Amygdala-ablated monkeys were found to be impaired in forming stimulusreward associations when submitted to pair-object discrimination (Phillips, Malamut, \& Mishkin, 1983; Spiegler \& Mishkin, 1981), whereas no effect of amygdaloid lesions was observed in rats on a delayed nonmatchingto-sample (DNMS) task (Aggleton, Blindt, \& Rawlins, 1989; Raffaele \& Olton, 1988). The fact that amygdala-

\section{VISUAL DISCRIMINATION}
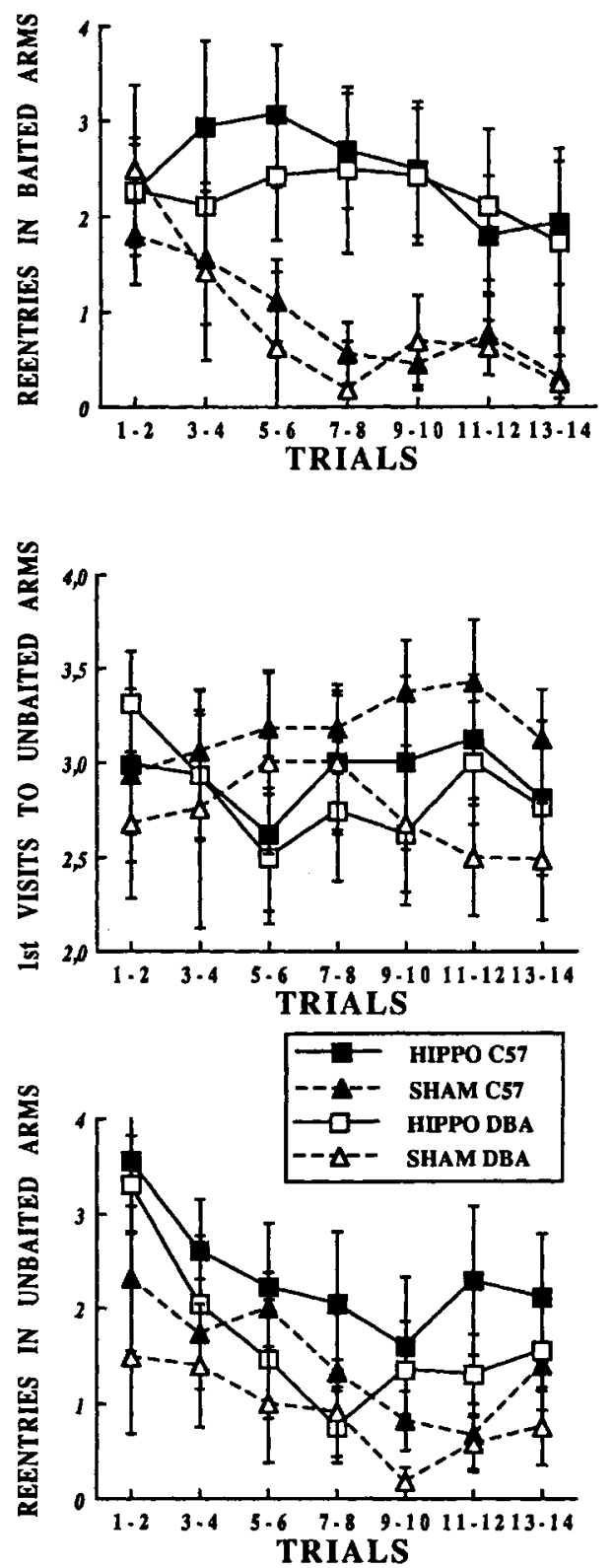

Figure 5. Visual discrimination performance in hippocampus- and sham-lesioned C57 and DB mice: number of reentries in baited arms (top), first visits to unbaited arms (middle), and number of reentries in unbaited arms (bottom). Each point corresponds to the mean $\pm S E M$ recorded on two consecutive daily trials (statistical analysis was performed on single trial values).

lesioned mice show no performance impairment in the cued maze is, therefore, in agreement with the DNMS data in rodents and, more generally, with the recent modification of Mishkin's two-circuit theory which now does not recognize an equivalent role for the hippocampus and the amygdala in visuospatial discrimination tasks (Mishkin, 1993). Finally, the fact that in the cued maze, C57 mice, irrespective of lesion, make more first 

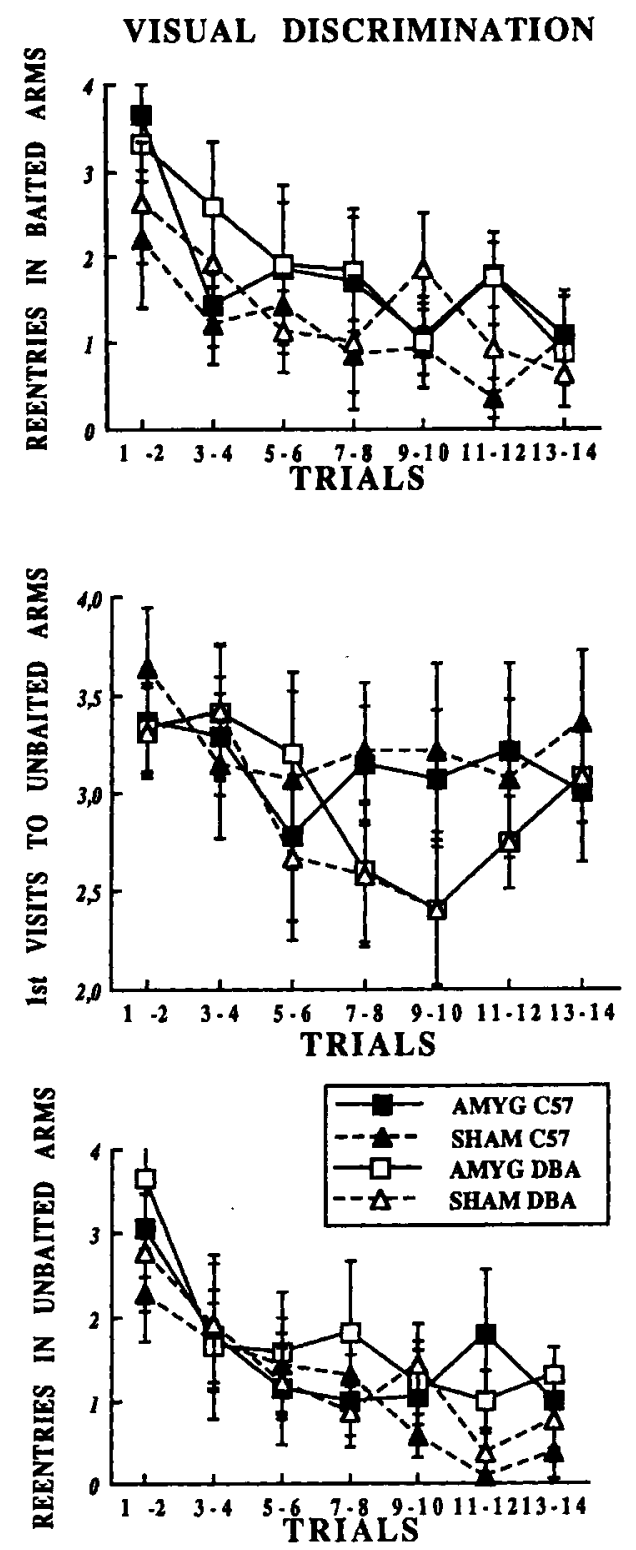

Figure 6. Visual discrimination performance in amygdala- and sham-lesioned C57 and DBA mice: number of reentries in baited arms (top), first visits to unbaited arms (middle), and number of reentries in unbaited arms (bottom). Each point corresponds to the mean \pm SEM recorded on two consecutive daily trials (statistical analysis was performed on single trial values).

visits to unbaited arms than DBA mice could be due to the high responsiveness to novelty previously described in the former strain (van Abeelen, 1975).

Taken together, the present results show a general impairing effect of hippocampal lesions on performance, regardless of strain or task. Amygdaloid lesions selectively affect spatial discrimination in the C57 strain but do not produce any visual discrimination decrement in either of the strains considered.

With regard to our working hypothesis, the assumption that a different circuitry might subserve strain- dependent spatial-learning abilities implicitly considered that distinct circuits would always have been associated with different levels of performance. However, reducing the number of arms to be discriminated in the spatial task abolished interstrain performance differences but did not modify the selective reactivity of $\mathrm{C} 57$ mice to amygdaloid lesions. It is therefore apparent that straindependent neural nets can be identified for specific types of information to be processed (e.g., spatial vs. visual), even if in particular experimental conditions there is no difference between the performance of DBA and C 57 mice.

It seems, therefore, that the different abilities shown by inbred mice in spatial tasks cannot be solely ascribed to the specific anatomical and functional organization of their hippocampus (Roullet \& Lassalle, 1992; Schwegler, Crusio, Lipp, \& Heimrich, 1988). The selective contribution of other brain areas to performance is probably crucial for the behavioral differences observed among strains and, likely, among individuals belonging to outbred populations. The question of whether the different areas recruited on each circuit cooperate by processing distinct but complementary memory attributes (Kesner \& DiMattia, 1987) or whether they are simply vicarious (Mishkin, 1978) remains to be investigated.

\section{REFERENCES}

Aggleton, J. P., Blindt, H. S., \& Rawlins, J. N. P. (1989). The effects of amygdaloid and combined amygdaloid-hippocampal lesions upon object recognition and spatial working memory in the rat. Behavioral Neuroscience, 103, 962-974.

Ammassari-Teule, M., \& CAPRioli, A. (1985). Spatial learning and memory, maze running strategies and cholinergic mechanisms in two inbred strains of mice. Behavioural Brain Research, 17, 9-16.

ammassari-Teule, M., Fagioli, S., \& Rossi-Arnaud, C. (1992). Genotype-dependent involvement of limbic areas in spatial learning and postlesion recovery. Physiology \& Behavior, 52, 505-510.

AmmassarI-TEule, M., \& Gozzo, S. (1982). Selective effects of hippocampal and frontal cortex lesions on a spatial learning problem in two inbred strains of mice. Behavioural Brain Research, 5, 189-197.

ammassari-Teule, M., Hoffmann, H. J., \& Rossi-Arnaud, C. (1993). Learning in inbred mice: Strain-specific abilities across three radial maze problems. Behavior Genetics, 23, 405-412.

Ammassari-Teule, M., \& MaHo, C. (1992). Choice behavior of fornix-damaged rats in radial maze error-free situations and subsequent learning. Physiology \& Behavior, 51, 563-567.

CRusio, W. E., SchWEgLeR, H., \& LiPP, H. P. (1987). Radial maze performance and structural variation of the hippocampus in mice: A correlation with mossy fiber distribution. Brain Research, 425, 182-185.

DunNeTt, S. B., Whishaw, I. Q., JoNES, G. H., \& Bunch, S. T. (1987). Behavioural, biochemical and histochemical effects of different neurotoxic amino acids injected into the nucleus basalis magnocellularis. Neuroscience, 20, 653-659.

Greene, E., \& Naranjo, J. N. (1986). Thalamic role in spatial memory. Behavioural Brain Research, 19, 123-131.

JARRARD, L. E. (1986). Selective hippocampal lesions and behavior: Implications for current research and theorizing. In R. L. Isaacson \& K. H. Pribram (Eds.), The hippocampus (Vol. 4, pp. 93-126). New York: Plenum.

Kesner, R. P., \& DiMattia, B. V. (1987). Neurobiology of an attribute model of memory. Progress in Psychobiology, Physiology \& Psychology, 12, 207-277.

Kesner, R. P., Farnworth, G., \& DiMattia, B. V. (1989). Double dissociation of egocentric and allocentric space following medial prefrontal and parietal cortex lesions in the rat. Behavioral Neuroscience, 103, 956-961. 
Kimble, D. P. (1975). Choice behavior in rats with hippocampal lesions. In R. L. Isaacson \& K. H. Pribram (Eds.), The hippocampus (Vol. 2, pp. 309-326). New York: Academic Press.

Kolb, B., Pittman, K., Sutherland, R. J., \& Whishaw, I. Q. (1982). Dissociation of the contributions of the prefrontal cortex and dorsomedial thalamic nucleus to spatially guided behavior in the rat. $\mathrm{Be}$ havioural Brain Research, 6, 365-378.

Marighetto, A., Micheau, J., \& JafFard, R. (1993). Relationships between testing-induced alterations of hippocampal cholinergic activity and memory performance on two-spatial tasks in mice. $B e$ havioural Brain Research, 56, 133-144.

Mishkin, M. (1978). Memory in monkeys severely impaired by combined but not by separate removal of amygdala and hippocampus. Nature, 273, 297-298.

MishKIN, M. (1993). Monkey hippocampus and recognition memory: What went wrong? European Brain \& Behaviour Society Abstracts, 25,24

OlToN, D. S. (1983). Memory functions and the hippocampus. In W. Seifert (Ed.), Neurobiology of the hippocampus (pp. 335-369). London: Academic Press.

Olton, D. S., Becker, J. T., \& Handelmann, G. E. (1979). Hippocampus, space, and memory. Behavioral \& Brain Sciences, 2, 313-365.

Packard, M. G., \& White, N. M. (1990). Lesions of the caudate nucleus selectively impair "reference memory" acquisition in the radial maze. Behavioral \& Neural Biology, 53, 39-50.

Phillips, R. R., Malamut, A. B. L., \& Mishkin, M. (1983). Memory for stimulus-reward associations in the monkey is more severely affected by amygdalectomy than by hippocampectomy. Society for Neuroscience Abstracts, 9, 638.

PoucET, B. (1990). A further characterization of the spatial problemsolving deficit induced by lesions of the medial frontal cortex in the rat. Behavioural Brain Research, 41, 229-237.

Raffaele, K. C., \& Olton, D. S. (1988). Hippocampal and amyg- daloid involvement in working memory for nonspatial stimuli. $B e$ havioral Neuroscience, 102, 349-355.

RENZI, P., \& SANSONE, M. (1971). Discriminated leverpress avoidance behavior in mice. Communications in Behavioral Biology, 6, 315 321.

Roberts, W. W., Dember, W. N., \& Brodwick, M. (1962). Alternation and exploration in rats with hippocampal lesions. Journal of Comparative \& Physiological Psychology, 55, 695-700.

Rossi-Arnaud, C., Fagioli, S., \& Ammassari-Teule, M. (1991). Spatial learning in two inbred strains of mice: Genotype-dependent effect of amygdaloid and hippocampal lesions. Behavioural Brain Research, 45, 9-16.

Roullet, P., \& Lassalle, J. M. (1992). Behavioural strategies, sensorial processes and hippocampal mossy fibre distribution in radial maze performance in mice. Behavioural Brain Research, 48, 77-85.

Schwegler, H., Crusio, W. E., Lipp, H.-P., \& Heimrich, B. (1988). Water maze learning in the mouse correlates with variation of hippocampal morphology. Behavior Genetics, 18, 153-165.

SPIEGLER, B. J., \& MishKIN, M. (1981). Evidence for the sequential participation of inferior temporal cortex and amygdala in the acquisition of stimulus-reward associations. Behavioural Brain Research, 3, 303-317.

UPCHURCH, M.; \& WEHNER, J. (1989). Inheritance of spatial learning ability in inbred mice: A classical genetic analysis. Behavioral Neuroscience, 103, 1251-1258.

van Abeelen, J. F. H. (1975). Genetic analysis of behavioural responses to novelty in mice. Nature, 254, 239-241.

WINOCUR, G. (1982). Radial-arm-maze behavior by rats with dorsal hippocampal lesions: Effects of cuing. Journal of Comparative \& Physiological Psychology, 96, 155-169.

(Manuscript received February 16, 1994; revision accepted for publication May 12, 1994.) 